\title{
How effective is instructional support for learning with computer simulations?
}

\author{
Marc Eckhardt • Detlef Urhahne • Olaf Conrad • Ute Harms
}

Received: 19 July 2010/Accepted: 19 March 2012/Published online: 3 April 2012

(C) The Author(s) 2012. This article is published with open access at Springerlink.com

\begin{abstract}
The study examined the effects of two different instructional interventions as support for scientific discovery learning using computer simulations. In two well-known categories of difficulty, data interpretation and self-regulation, instructional interventions for learning with computer simulations on the topic "ecosystem water" were developed and tested using a sample of 124 eighth graders in science classes. The results demonstrate the effectiveness of instructional support for domain-specific factual, conceptual, and procedural knowledge acquisition. Students who received either only instructional support for data interpretation or only for self-regulation achieved the highest learning outcomes. However, a combination of instructional support for data interpretation and self-regulation seemed detrimental for knowledge acquisition. Students who received instructional interventions for both data interpretation and self-regulation also showed the highest values of perceived cognitive load. High cognitive load could be a reason for why a combination of particular instructional interventions does not lead to the expected positive learning outcomes.
\end{abstract}

Keywords Computer simulation - Instructional support · Data interpretation · Self-regulated learning $\cdot$ Cognitive load $\cdot$ Secondary school students

\footnotetext{
M. Eckhardt $(\bowtie)$

Department of Biology Education, IPN - Leibniz Institute for Science and Mathematics Education at the University of Kiel, Olshausenstr. 62, 24098 Kiel, Germany

e-mail: eckhardt@ipn.uni-kiel.de

D. Urhahne

Department of Educational Psychology, Martin-Luther-University of Halle-Wittenberg, Wittenberg, Germany

O. Conrad

Department of Earth Sciences, University of Hamburg, Hamburg, Germany

U. Harms

Department of Biology Education, IPN - Leibniz Institute for Science and Mathematics Education at the University of Kiel, Kiel, Germany

U. Harms

ISV - Department of Social and Welfare Studies, Linköping University, Linköping, Sweden
} 
Among computer-based learning programs, computer simulations are considered to be the most technically sophisticated option for offering various benefits for the teaching and learning of science (Blake and Scanlon 2007). A computer simulation is an interactive program that contains a model of a natural or artificial system or process (Blake and Scanlon 2007; de Jong and van Joolingen 1998). It gives learners opportunities to experiment harmlessly and to simulate processes in an e-learning environment (Urhahne et al. 2000). Computer simulations provide learners with chances to actively engage in simulated scenarios. Learners can change given parameters of their own choice and directly observe the consequences of their manipulations in dynamic output. Knowledge can be acquired in an interactive and independent manner by individualizing learning processes and adjusting learning time and speed to current requirements.

Computer simulations fit best with principles of scientific discovery learning. Learners are asked to infer the characteristics underlying the scenarios when they explore the principles, concepts, rules, and terms of simulated experiments (van Joolingen et al. 2005). Learners are required to discover the model behind the simulation (de Jong et al. 1994). In recent decades, discovery learning has moved away from the concept of pure discovery. For several years, discovery learning has relied on a more systematic approach adapted from theories of scientific discovery (Bruner 1961; de Jong and van Joolingen 1998; van Joolingen and de Jong 1997; van Joolingen et al. 2005). This notion is referred to as scientific discovery learning (Klahr and Dunbar 1988; Klahr et al. 1993). It presupposes that students will follow a more or less scientific approach based on problem solving. Scientific discovery learning is in line with aspects of inquiry learning, including processes such as predicting (stating a possible simulation outcome), conducting (carrying out the simulated experiment and collecting data), and reasoning (drawing conclusions about the simulation outcome; cf. National Research Council 1996; de Jong 2006; Reid et al. 2003).

Empirical studies have pointed out that students frequently encounter problems with processes of scientific discovery learning (de Jong and van Joolingen 1998; de Jong et al. 1998; Kirschner et al. 2006; Manlove et al. 2006; Rey 2010; Zhang et al. 2004). However, by providing learning environments for students by using computer simulations, specific instructional support can foster successful knowledge acquisition (de Jong and van Joolingen 1998). The aim of this study was to examine students' awareness of their own inquiries with computer simulations and to determine what kind of instructional support is needed to improve learning outcomes. In two categories of scientific discovery learning, namely, data interpretation and self-regulation, instructional support was given, and we examined whether they help to increase learners' domain-specific knowledge.

\section{Theoretical background}

There is ample empirical evidence to support the conclusion that pure and independent exploration of scientific principles, concepts, and rules does not lead to effective learning outcomes (de Jong and Njoo 1992; Leutner 1993; Mayer 2004; Rieber and Parmley 1995). This phenomenon may be explained by intrinsic problems that learners possess with discovery learning (de Jong and van Joolingen 1998). Scientific discovery learning with computer simulations, in particular, requires the ability of self-directed learning as well as the learner's awareness about his or her own learning processes. According to de Jong and van Joolingen (1998), four categories of difficulties that learners may encounter during scientific discovery learning can be distinguished: generating verifiable hypotheses, designing meaningful experiments, interpreting experimental data, and the self- 
regulation of learning processes (de Jong et al. 1998; Manlove et al. 2006). To improve their learning outcomes, learners need instructional support in order to overcome these difficulties (de Jong and van Joolingen 1998; Urhahne and Harms 2006; van Joolingen et al. 2007).

Instructional support to enhance learning with computer simulations can be given on different occasions during the learning process. Zhang et al. (2004) distinguished three spheres of learning support in their scheme of scientific discovery learning with computer simulations: (a) Interpretative support scaffolds learners to access and activate prior knowledge as well as to generate appropriate hypotheses; (b) Experimental support scaffolds learners in designing verifiable scientific experiments, predicting and observing simulation outcomes, and drawing appropriate conclusions; (c) Reflective support helps learners to increase their self-awareness of the learning process and supports the activation of abstract and reflective integration of their discoveries. The four categories of learning difficulties with computer simulations suggested by de Jong and van Joolingen (1998) can be integrated (cf. Zhang et al. 2004) in these three spheres. The classification scheme of Zhang et al. (2004) provides a theoretical framework for our study and is used in the following to explain different options for instructional support.

Interpretative support scaffolds learners' awareness about the meaningfulness of the discovery process. To generate appropriate hypotheses and to construct a coherent understanding, learners need to activate their prior knowledge. Interpretative support is intended to foster problem representation, ease access to learners' prior experiences, facilitate the use of the computer simulation, and is usually given before the learner starts to interact with the computer simulation. An effective and supportive intervention, for example, is to provide accessible domain-specific background information, optionally available to the learner during problem solving (Leutner 1993; Reid et al. 2003). Concrete assignments that learners are required to work on with the aid of the computer simulation are another kind of approved instructional support for knowledge acquisition (de Jong et al. 1998; de Jong 2006; Vreman-de Olde and de Jong 2006). Assignments offer opportunities to support learners' goal-setting behaviors (de Jong et al. 1998). They provide learners with a well-directed inquiry on concrete questions that can be solved by means of the computer simulation. Thereby, learners can be directed to discover relations between two or more variables. Worked-out examples can be considered to be another kind of interpretative support and have been shown to have positive effects on learning outcomes in numerous studies (e.g., Nerdel and Prechtl 2004; Renkl 2005; Renkl and Atkinson 2002). Worked-out examples introduce learners to a specific problem, suggest steps for solving this problem, and describe the solution in detail. In particular, they support learners' acquisition of conceptual knowledge as well as problem-solving competencies.

Experimental support scaffolds learners' processes of scientific inquiry during the interaction with the computer simulation. This type of support scaffolds learners in their attempts to design adequate scientific experiments. Effective interventions of experimental support for knowledge acquisition are the gradual and cumulative introduction of handling the computer simulation, the explanation of important simulation parameters located in the computer program, the request to predict a possible simulation outcome by the learner, as well as the request to describe and to interpret the simulation outcome by the learner (Urhahne and Harms 2006). The prediction of possible simulation outcomes by the learners in a study by Lewis Stern, and Linn (1993) tended to lead to higher knowledge gains than in a control group. Through the gradual and cumulative introduction of a computer simulation, learners receive all necessary and relevant information to handle the simulation and work on assignments. Thereby, highly informative computer simulations obtain a 
structure of increasing complexity (White 1998), which helps to avoid a possible cognitive overload due to an overabundance of information. Further experimental support can be given by describing and justifying the simulation outcome. A study by Moreno and Mayer (2005) indicated higher domain-specific knowledge acquisition as a result of justifying one's own simulation outcome.

Reflective support scaffolds the integration of new information as a result of discoveries after the interaction with the computer simulation. This kind of support helps to increase learners' self-awareness of the learning process and reflective abstraction as well as the integration of information discovered using the computer simulation. This can be achieved, for instance, by means of an instructional approach that scaffolds learners' metacognitive knowledge by prompting reflective processes. White (1998) examined whether a reflective assessment tool could aid learners while assessing and justifying their own inquiries. After carrying out computer-simulated experiments, students were provided with the opportunity to discuss their own as well as their schoolmates' inquiries. The reflective support led to positive effects in conceptual knowledge acquisition (White and Frederiksen 1998).

For study purposes, we focused on learners' difficulties in data interpretation and selfregulated learning. In a review, de Jong and van Joolingen (1998) indicated that particular instructional interventions for supporting data interpretation and self-regulation were effective for learning with computer simulations. Similarly, Urhahne and Harms (2006) inferred in a literature review that particular instructional support for data interpretation and self-regulation showed high effectiveness with regard to knowledge acquisition. In addition, no detrimental effects on learning outcomes could be found when learning with computer simulations was supported by instructional interventions for data interpretation and self-regulation (Urhahne and Harms 2006).

To enhance the effectiveness of data interpretation, it seems helpful to offer learners feedback about implemented actions (Lin and Lehmann 1999; Moreno 2004). Differentiated feedback from the computer program about the simulation outcome can support learners' knowledge acquisition. In a study by Moreno (2004), knowledge retention and transfer were promoted as learners received either task-related explanatory feedback or corrective feedback from the computer program. Other studies have substantiated the assumption that learners' descriptions and interpretations of the simulation outcome lead to more effective knowledge acquisition. Lin and Lehmann (1999) conducted a study in which learners were requested to justify the simulation outcome after they made use of computer-simulated experiments. This kind of instructional support led to a significant improvement of knowledge application on a transfer task. In 19 cited studies on learning mathematics and computer science, Webb (1989) found that giving explanations was positively related to achievement, whereas receiving explanations had few positive effects on achievement.

Learning with computer simulations puts high demands on learners' self-regulation abilities. It implies that learners can acquire new contents in an autonomous and meaningful way. Computer-based learning environments should be appropriately structured to enable self-regulated learning processes. Questions of instructional design are critical when learners should not be overloaded with information (Sweller 2005). In cognitive load theory, Sweller (2005) connected the instructional design of learning environments to the limited capacity of human working memory. Although the number of elements that can be simultaneously processed in human working memory is limited (Miller 1956), too much information can result in cognitive overload. Inadequately designed learning environments may induce a high working memory load that can be detrimental to learning (Kirscher et al. 2006). 
Self-regulated learning might be efficiently promoted by self-reflective tasks. Such reflective self-assessment, a method to improve awareness about one's own inquiry, has positive effects on knowledge acquisition (White and Frederiksen 1998). After learners had carried out computer-simulated experiments, they were requested to reflect on their own and their schoolmates' inquiries with regard to given criteria (White and Frederiksen 1998). The method supported learners in the self-reflection phase (Zimmermann et al. 1996; Zimmermann and Tsikalas 2005) and proved to be effective with respect to conceptual knowledge acquisition.

The impact of particular instructional interventions that have called upon learners' reflective activities, such as justifications for simulation outcomes, as well as hints or tasks to encourage reflection about one's own inquiry have been examined less systematically. However, these instructional interventions possess the potential to enhance simulationbased learning. Hence, instructional interventions to support data interpretation and selfregulation were analyzed, developed, and tested. It was assumed that the instructional interventions for data interpretation and self-regulation when learning with computer simulations could effectively foster domain-specific knowledge acquisition.

Aim and hypotheses

The aim of the study was to determine what kind of instructional support for data interpretation and for self-regulation when learning with computer simulations is useful for increasing learners' domain-specific knowledge. Subsequent hypotheses regarding instructional support for data interpretation and self-regulated learning were pursued:

The first hypothesis argued that learners' self-generated explanations of the simulation outcome would be more effective than explanatory feedback of the computer program, and this in turn would be more effective than no feedback at all (Chi et al. 1989, 1994; Lin and Lehmann 1999; Moreno 2004).

The second hypothesis proposed that reflecting on the learning process would lead to higher knowledge gains than no reflection on simulated experiments (White and Frederiksen 1998).

The third hypothesis argued that a combination of instructional interventions for data interpretation and self-regulation would show cumulative effects on knowledge gains as long as cognitive load was not too high (Sweller 2005).

\section{Method}

Participants

The sample consisted of 124 eighth grade secondary school students from six different classes in northern Germany. The ages of the 69 girls and 55 boys ranged from 13 to 16 years $(M=14.50, S D=0.23)$. The number of students in the different classes varied between 18 and 24. The distributions of the girls and boys in the six classes were similar. Before the study, the students had received no formal instruction on the water-ecological topic to be investigated. However, the participants had advanced skills in handling the computer program and had received formal instruction on the mathematical contents that were necessary to understand the graphical relations of the computer simulation. All students participated in the study voluntarily. 
Material

\section{Content}

The topical framework "relationships between organisms" was selected to test the instructional interventions for data interpretation and self-regulation. Relationships between living organisms are an important issue in science teaching at all class levels because food chains and food webs are crucial for the comprehension of more complex concepts in biology. The concrete topic of the computer simulation "population dynamics and predator-prey relationships" is considered to be a relevant and difficult part of science education (Finley et al. 1982) and is an integral component of the current biology curriculum for eighth graders in German secondary schools. Students frequently display problems in understanding predator-prey relationships (Gallegos et al. 1994). For example, they often reveal difficulties in understanding the two-sided dependency of predator and prey (Griffiths and Grant 1985). Computer simulations as educational tools for modeling dynamic predator-prey relationships have been established to facilitate visualizations of how various factors of population dynamics interact (Cook 1993; van Joolingen et al. 1997; Lutterschmidt and Schaefer 1997).

\section{Computer program}

A water-ecological computer program containing a computer simulation as well as instructional interventions for data interpretation and self-regulation were developed and tested in pilot studies. Twenty-eight biology teachers were interviewed for the development of the computer program. The interview data pointed out that from the teachers' perspective, "external influences on water" were perceived as the most important aspects of the water ecosystem. For this reason, the computer program "SimBioSee", containing ecological fundamentals and a computer simulation on the predator-prey relationship between the two domestic fish species "pike" and "rudd", was designed. The computer program itself is divided into four sequential parts: an introduction, information pages, a worked-out example, and a computer simulation. At the beginning, learners receive an introduction to the computer program and the computer simulation in the form of a manual. Information pages as a kind of interpretative support (Zhang et al. 2004) permit learners to have permanent access to (water-) ecological fundamentals during their interactions with the computer program by means of a navigation bar and linked headlines. Offering learners permanent access to information such as domain-specific facts, concepts, principles, or terms during their interactions with the computer program may have positive effects on knowledge acquisition (Leutner 1993), whereas providing this information beforehand seems less effective (Elshout and Veenman 1992; Leutner 1993). Furthermore, a workedout example is integrated into the computer program as well. Worked-out examples as instructional support have shown positive effects on knowledge acquisition (Atkinson et al. 2000). For novice learners in particular, applied worked-out examples are effective for increasing problem solving skills (Biesinger and Crippen 2010; Kalyuga et al. 2001; Yaman et al. 2008). The worked-out example is followed by a detailed description of problem-solving processes with the aid of the computer simulation. Learners obtained the problem's solution as an image of the simulation outcome with a verbal description and a biological interpretation.

The computer simulation, which is integrated into the computer program, is presented as a diagram containing the numbers of predators and prey as dependent variables and time as 


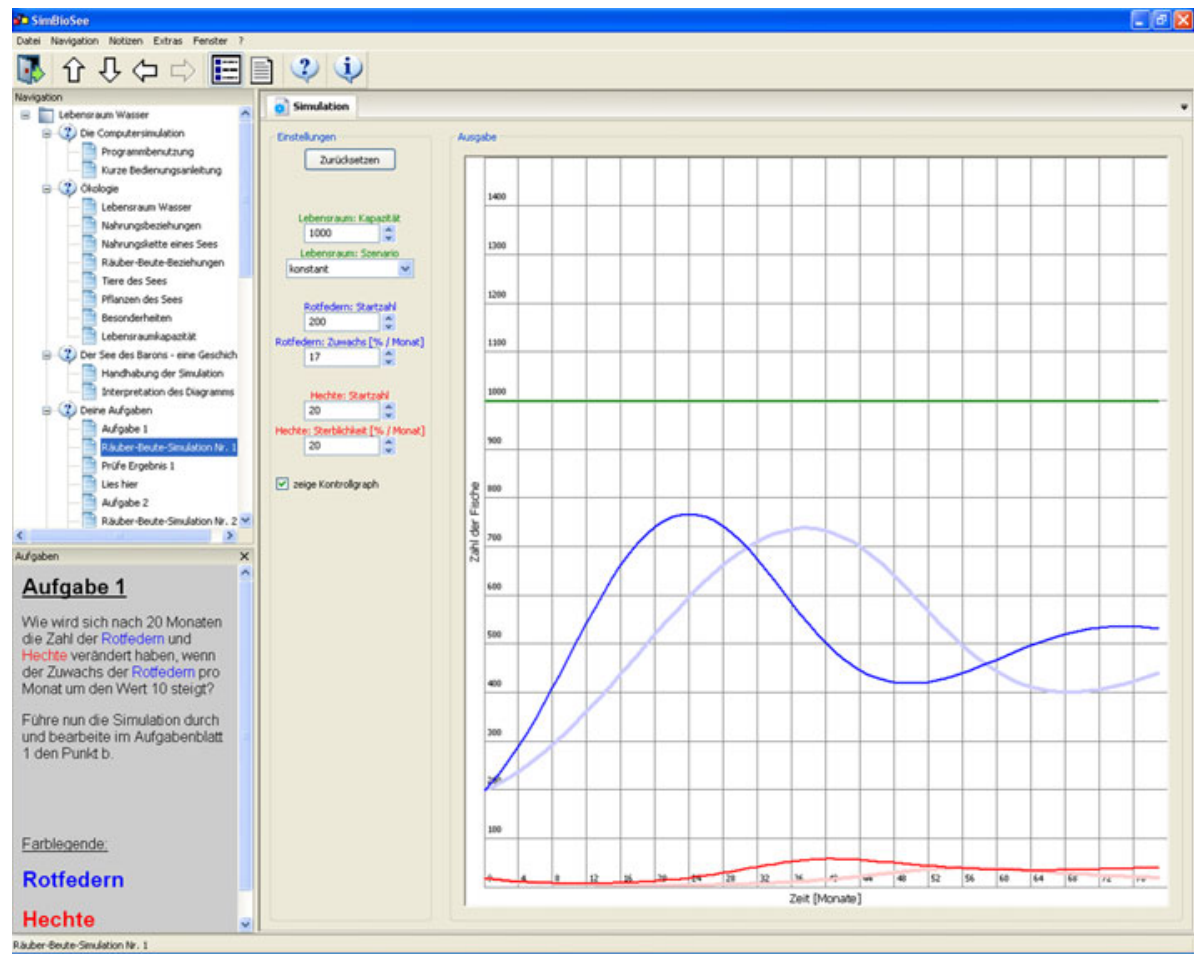

Fig. 1 Displayed screen of the computer simulation in the computer program "SimBioSee". On the left is the navigation bar with linked headlines to information sides presented accordingly on the right. There is an additional field containing an assignment below the navigation bar. The displayed simulation outcome on the right illustrates the number of each fish species depending on time. The red curve shows the number of predators (pikes) and the blue curve displays the number of prey (rudds). Through changing parameters located to the left of the diagram, the curves can be modified. The simulation outcome can be compared with the lighter colored initial conditions of the curves. (Color figure online)

the independent variable (see Fig. 1). For each of the two selected species, the numbers of fish are presented as different colored curves. Parameters for modifying the curves are located on the left side of the diagram. Transparent curves in the diagram represent the initial conditions and allow for easy comparisons with the simulation outcome.

\section{Assignments}

A number of concrete assignments have to be solved using the computer simulation. The basic frame of the assignments, administered on paper, is aligned with a POE (predictobserve-explain) strategy (White and Gunstone 1992). At the beginning, learners are asked to predict possible consequences of external influences on the water ecosystem. After carrying out the computer-simulated experiment, they are asked to compare the simulation outcome with the prediction. At the end and depending on the treatment condition, each assignment is extended by requesting or referring to a description and a biological interpretation of the simulation outcome. In addition, the contents of an assignment are displayed next to the computer simulation below the navigation bar (see Fig. 1). An example of an assignment is given in the "Appendix". 
Independent variables

The independent variables used in the study were instructional support for data interpretation and for self-regulation. They are described in the following.

\section{Support for data interpretation}

As an instructional intervention to support data interpretation, learners either (a) were requested to describe and scientifically interpret the simulation outcome (Lin and Lehmann 1999) or (b) received a description and biological interpretation of the simulation outcome from the computer program (Moreno 2004). In the solution condition in which participants were asked to generate a solution, learners were requested to describe and to interpret their own simulation outcome in written form on their assignment (see "Appendix"). In the solution condition that was given to them, a description and biological interpretation of the simulation outcome after conducting an experiment appeared on the computer screen (see Fig. 2). In the no solution condition, students received no instructional support for data interpretation.

\section{Support for self-regulation}

As an instructional intervention to support self-regulation, learners were asked to assess and reflect on their own inquiry (White and Frederiksen 1998; Zimmermann and Tsikalas 2005). Self-assessment and reflection were done with the aid of a reflective assessment tool integrated into the computer program but in a separate area. It was used after learners had finalized all given assignments. According to the ThinkerTools Curriculum (White and Frederiksen 1998; White et al. 1999), learners were initially required to assess their own inquiry with a 5-point rating scale. Predetermined questions referring to different phases of the inquiry cycle were intended to aid learners' self-assessments. Subsequently, learners were prompted to justify their assessments in written form (see Fig. 3). Half of the students received this kind of instructional intervention, whereas the other half of the students did not get instructional support for self-regulation.

Dependent variable

The students' domain-specific knowledge gain was the dependent variable in the study operationalized by means of a domain-specific knowledge test.

\section{Knowledge test}

A paper-and-pencil test was developed and tested in two prior investigations to assess three types of students' domain-specific knowledge. The different knowledge types can be defined as follows: Factual knowledge consists of "knowing that" or can be described as knowledge about domain-specific fundamentals (Anderson and Krathwohl 2001). Conceptual knowledge is more complex and organized than factual knowledge and includes knowledge about categories and classifications as well as the relations between them (Anderson and Krathwohl 2001). Procedural knowledge consists of "knowing how" or knowledge of the steps required to attain various goals (Byrnes and Wasik 1991). In total, the knowledge test is comprised of 16 multiple-choice items. Factual knowledge was measured using five items, conceptual knowledge was measured using seven items, and procedural knowledge was assessed using four items. Each item could be answered by 


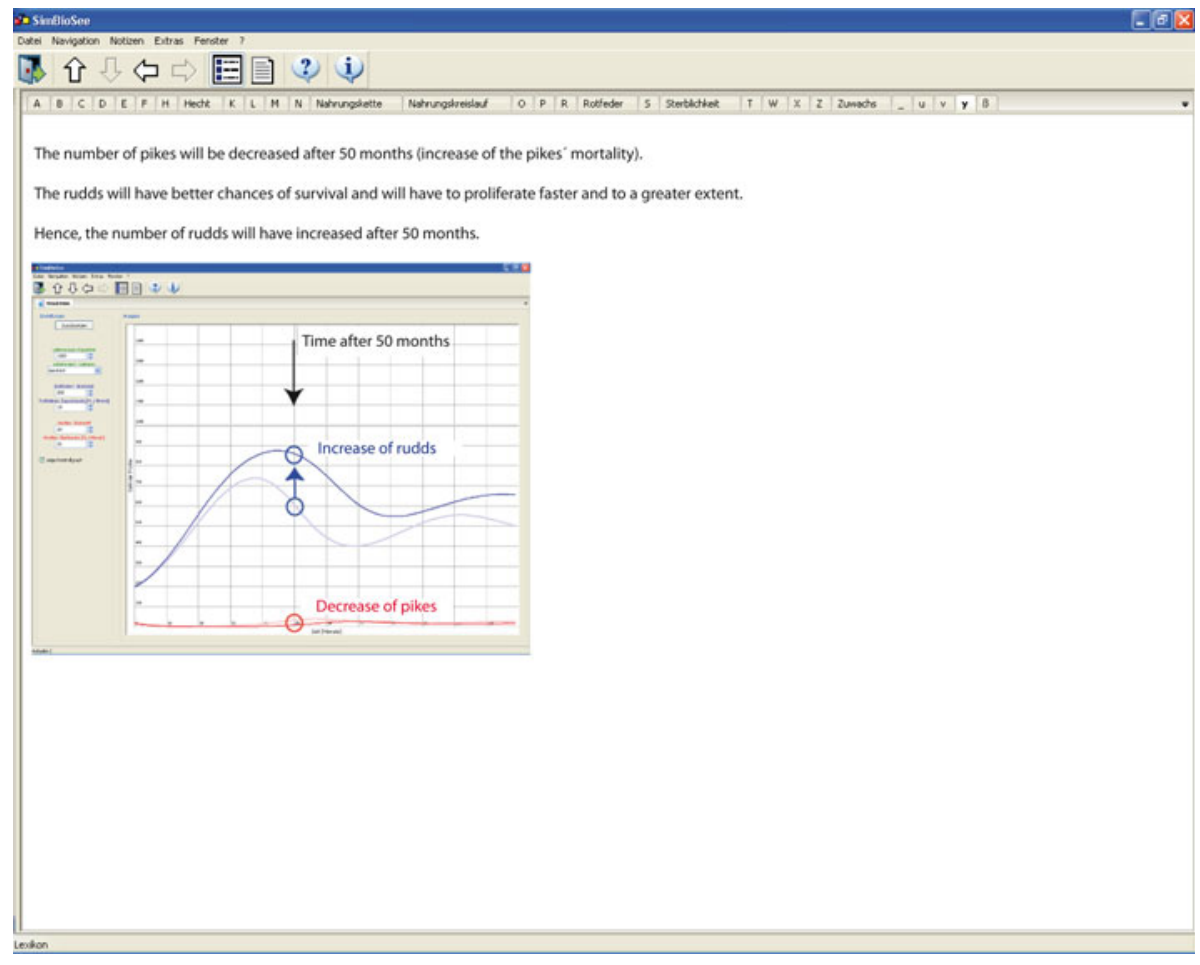

Fig. 2 Description and biological interpretation of a simulation outcome as an instructional intervention for data interpretation given by the computer program "SimBioSee"

means of the computer program. Sample items of each knowledge category are shown in Table 1. A subsequent factor analysis revealed that the three knowledge types did not represent single factors but were highly interrelated. For this reason, the results of the knowledge test were summed into one construct. Cronbach's alpha for the knowledge test was .68 for the first posttest and .76 for the second posttest.

\section{Perceived cognitive load}

Perceived cognitive load during the learners' interaction with the computer program was assessed through a self-report paper-and-pencil test instrument according to Urhahne (2002) by making use of a 5-point rating scale. In contrast to the most commonly used instrument by Paas (1992), the questionnaire by Urhahne (2002) contains eight items instead of only one (de Jong 2010). This allows for a broader differentiation regarding participants' perceived cognitive load and an estimation of the questionnaire's reliability. Cronbach's alpha for perceived cognitive load was .86 in the first session and also .86 in the second session. A sample item is "How often did you have the impression that the program offered too much information?"

\section{Procedure}

The study was conducted during regular science lessons in six different classes. Three days before the first use of the computer program in the first session, every participant had to 


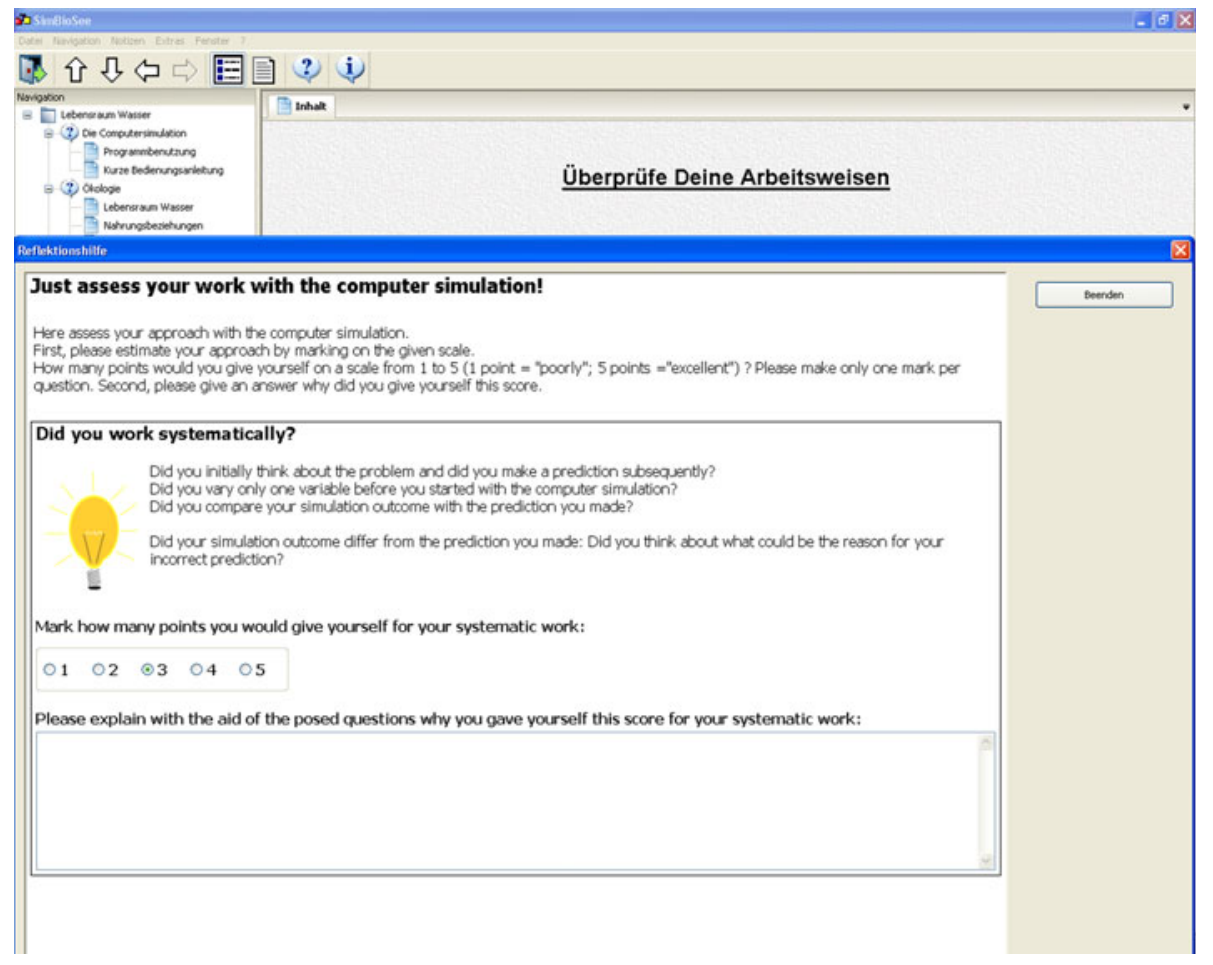

Fig. 3 Displayed screen of a section of the reflective assessment tool integrated into the computer program. After learners had conducted all computer-simulated experiments, they were required to assess their own inquiry on a 5-point scale. Afterwards, they had to explain their score based on their inquiry and why this score seemed to be appropriate

take the pretest, which was comprised of factual, conceptual, and procedural knowledge questions. Learning with the computer simulation "SimBioSee" was repeatedly done on two different days with a 10-day interval in between. The time span between the sessions was expected to reduce the influence of Posttest 1 on learners' answer patterns on Posttest 2. During each learning phase, every student worked alone on four different assignments for $60 \mathrm{~min}$ on a single laptop. The participants followed a POE strategy to complete the assignments with the aid of the computer simulation. After that, every student filled out the paper-and-pencil knowledge posttest. All items on the knowledge test could already be answered by means of the computer program after the first learning phase. The administration and the items on the knowledge test were the same in each session. Students required approximately $20 \mathrm{~min}$ to take the posttest. About 5 min immediately after the posttest, the participants assessed their perceived cognitive load during the learning process. Each session in the classes lasted up to $90 \mathrm{~min}$.

\section{Design}

The study was based on a repeated measures $3 \times 2$ factorial design. As students required different introductions to handle the instructional interventions appropriately, groups were built on the class level. Thereby, students who were required to describe and interpret their 
Table 1 Sample items for measuring factual, conceptual, and procedural knowledge

\begin{tabular}{|c|c|c|}
\hline Factual knowledge & Conceptual knowledge & Procedural knowledge \\
\hline What is plankton? & $\begin{array}{l}\text { If predators in a lake become } \\
\text { extinct, what implications could } \\
\text { this have for the prey? }\end{array}$ & $\begin{array}{l}\text { How many variables should you change } \\
\text { simultaneously in conducting a } \\
\text { computer-simulated experiment? }\end{array}$ \\
\hline $\begin{array}{l}\text { (a) Small animals and } \\
\text { algae floating freely in } \\
\text { the water }\end{array}$ & $\begin{array}{l}\text { (a) The number of prey won't } \\
\text { increase }\end{array}$ & $\begin{array}{l}\text { (a) One variable. Thus you can retrace } \\
\text { the simulation outcome based on the } \\
\text { impact of this variable }\end{array}$ \\
\hline $\begin{array}{l}\text { (b) Plants attached to the } \\
\text { floor of the body of } \\
\text { water }\end{array}$ & $\begin{array}{l}\text { (b) The number of prey could } \\
\text { increase and will decrease } \\
\text { subsequently }\end{array}$ & $\begin{array}{l}\text { (b) Two variables. Thus it will be } \\
\text { possible to compare the impact of these } \\
\text { two variables }\end{array}$ \\
\hline $\begin{array}{l}\text { (c) Small animals and } \\
\text { algae living on the floor } \\
\text { of the body of water }\end{array}$ & $\begin{array}{l}\text { (c) The number of prey could } \\
\text { increase up to the capacity limit }\end{array}$ & $\begin{array}{l}\text { (c) All variables simultaneously. A } \\
\text { simulation offers this opportunity in } \\
\text { order to save time while conducting } \\
\text { experiments }\end{array}$ \\
\hline $\begin{array}{l}\text { (d) Plant remains floating } \\
\text { freely in the water }\end{array}$ & $\begin{array}{l}\text { (d) The number of prey could } \\
\text { increase but not up to the } \\
\text { capacity limit }\end{array}$ & (d) All variables under investigation \\
\hline $\begin{array}{l}\text { (e) Decomposed nutrients } \\
\text { floating freely in the } \\
\text { water }\end{array}$ & $\begin{array}{l}\text { (e) The number of prey will } \\
\text { increase beyond the capacity } \\
\text { limit }\end{array}$ & $\begin{array}{l}\text { (e) All variables offered by the computer } \\
\text { simulation }\end{array}$ \\
\hline
\end{tabular}

Note The correct answer for each item is written in italics

own simulation outcome could be introduced more extensively than students who received the description and interpretation from the computer program. The instructional interventions for data interpretation and self-regulation were completely crossed and created six experimental conditions including a control group in which learners did not receive instructional support for data interpretation or for self-regulation (see Table 2). The six groups varied with respect to the instructional interventions for data interpretation and selfregulation. All participants worked on the same assignments in their own classrooms in the presence of the biology teacher and the examiner. The laptops were all of the same type and provided by the Institute for Science and Mathematics Education. Except for the instructional interventions that were tested, the computer program "SimBioSee" was the same in each condition. During the sessions, learners did not exchange any information. The learners who participated in all three testing time points were equally distributed among the six research conditions. Results of a Chi-square test revealed no significant differences between the numbers of participants in the experimental groups, $\chi^{2}(2)=$ $.79, n s$.

Table 2 Distribution of participants in the control and experimental conditions

\begin{tabular}{|c|c|c|c|}
\hline \multirow[t]{2}{*}{ Self-regulation } & \multicolumn{3}{|l|}{ Data interpretation } \\
\hline & $\begin{array}{l}\text { No solution } \\
\text { (NS) }\end{array}$ & $\begin{array}{l}\text { Given solution } \\
\text { (GiS) }\end{array}$ & $\begin{array}{l}\text { Generated solution } \\
(\mathrm{GeS})\end{array}$ \\
\hline $\begin{array}{l}\text { No reflective support } \\
\text { (NR) }\end{array}$ & $\begin{array}{l}n=20 \\
\text { (NS/NR, control) }\end{array}$ & $\begin{array}{l}n=18 \\
(\mathrm{GiS} / \mathrm{NR})\end{array}$ & $\begin{array}{l}n=21 \\
(\mathrm{GeS} / \mathrm{NR})\end{array}$ \\
\hline $\begin{array}{l}\text { Reflective support } \\
\text { (R) }\end{array}$ & $\begin{array}{l}n=18 \\
(\mathrm{NS} / \mathrm{R})\end{array}$ & $\begin{array}{l}n=24 \\
(\mathrm{GiS} / \mathrm{R})\end{array}$ & $\begin{array}{l}n=23 \\
(\mathrm{Ges} / \mathrm{R})\end{array}$ \\
\hline
\end{tabular}




\section{Results}

Knowledge gains

Domain-specific knowledge gains were examined with respect to the instructional interventions of data interpretation and self-regulation. A multivariate repeated measures analysis of variance (MANOVA) for the dependent variable domain-specific knowledge with the two instructional interventions as between-subjects factors and the testing time points as a within-subjects factor showed a significant main effect of testing time points, $F(2,117)=74.24, p<.001, \eta^{2}=.56$. This means that the learners showed significant knowledge gains from the pretest to the posttests across the conditions (see Table 3). Furthermore, a significant interaction of instructional support for data interpretation and instructional support for self-regulation was detected, $F(2,118)=4.44, p<.05, \eta^{2}=.07$. This means that the conditions profited differently from the provided instructional support. In particular, the participants of the conditions NS/R and GeS/NR who received either only instructional support for data interpretation or only instructional support for self-regulation showed the highest knowledge gains. Comparatively low knowledge gains over the two testing time points were shown by learners in the GeS/R condition who were requested to describe and to interpret their own simulation outcome and who had to reflect on their scientific discovery learning. Except for the participants in the GeS/R condition who received instructional support for data interpretation as well as instructional support for selfregulation, the learners in the remaining conditions showed a significant knowledge increase from the pretest to Posttest 1. With the exception of the control group (NS/NR), learners in all other conditions showed significant knowledge gains from the pretest to Posttest 2.

Subsequent analyses were computed to reveal whether the knowledge gains of the instructional support conditions were higher than those of the control group, which did not receive support for data interpretation or for self-regulation. Five repeated measures analyses of variance were conducted whereby comparisons were made in pairs between one of the experimental conditions and the control group (NS/NR) across the three measurement points. The conditions with the given solution and no reflective support (GiS/NR), $F(1,36)=4.63, p<.05, \eta^{2}=.11$, the given solution and reflective support (GiS/R), $F(1$, $42)=5.68, p<.05, \eta^{2}=.12$, and the generated solution and no reflective support $(\mathrm{GeS} /$ $\mathrm{NR}), F(1,39)=9.06, p<.01, \eta^{2}=.19$, performed significantly better than the control group. No significant differences could be found between the control group and the condition with no solution and reflective support (NS/R), $F(1,36)=.42, n s, \eta^{2}=.01$, as well as the condition with the generated solution and reflection $(\mathrm{GeS} / \mathrm{R}), F(1,41)=.24, n s$, $\eta^{2}=.01$.

Furthermore, we analyzed whether the instructional interventions for data interpretation and self-regulation had an effect on knowledge acquisition when pretest scores were taken into account as a covariate. Pretest results were additionally recognized as there appeared to be significant differences between the conditions, $F(5,118)=2.51, p<.05$. For this reason, analyses of covariance (ANCOVA) with Posttest 1 as the dependent variable and the pretest results as a covariate were performed. The ANCOVA revealed no significant main effects of instructional support for data interpretation, $F(2,117)=1.74, n s, \eta^{2}=.03$, and instructional support for self-regulation, $F(1,117)=.69, n s, \eta^{2}=.01$. However, a significant interaction between instructional support for data interpretation and instructional support for self-regulation could be detected, $F(2,117)=16.98, p<.001, \eta^{2}=.23$. The results of the ANCOVA for Posttest 2 were along the same lines: A significant interaction between instructional support for data interpretation and instructional support 


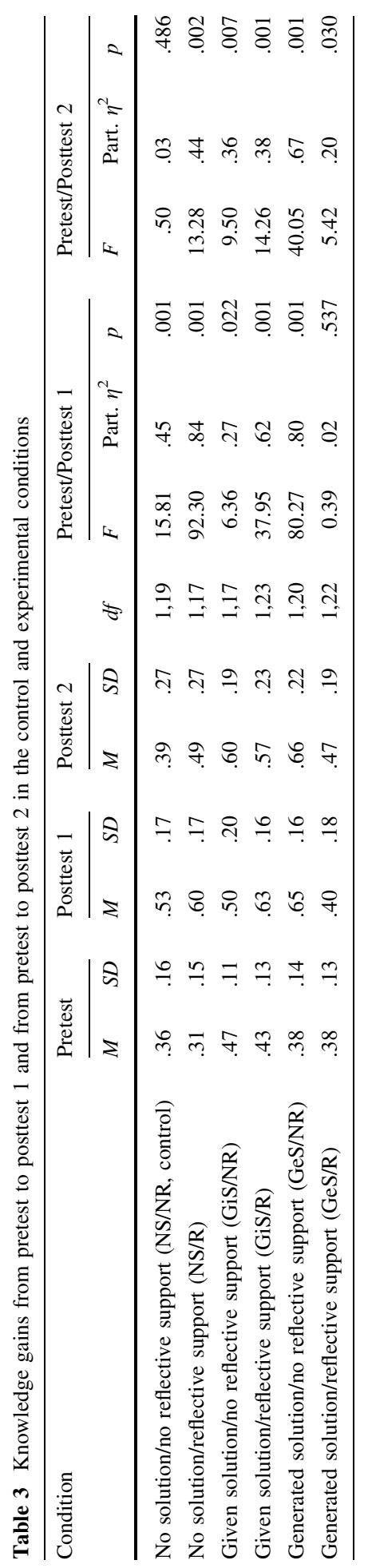


Table 4 Perceived cognitive load scores in sessions 1 and 2

\begin{tabular}{|c|c|c|c|c|}
\hline \multirow[t]{2}{*}{ Condition } & \multicolumn{2}{|c|}{ Session 1} & \multicolumn{2}{|c|}{ Session 2} \\
\hline & $M$ & $S D$ & $M$ & $S D$ \\
\hline No solution/no reflective support (NS/NR, control) & 2.23 & 0.57 & 2.23 & 0.54 \\
\hline No solution/reflective support (NS/R) & 2.32 & 0.62 & 2.36 & 0.79 \\
\hline Given solution/no reflective support (GiS/NR) & 2.35 & 0.36 & 2.60 & 0.63 \\
\hline Given solution/reflective support (GiS/R) & 2.43 & 0.68 & 2.39 & 0.75 \\
\hline Generated solution/no reflective support (GeS/NR) & 2.14 & 0.48 & 1.94 & 0.42 \\
\hline Generated solution/reflective support $(\mathrm{GeS} / \mathrm{R})$ & 3.23 & 0.72 & 3.10 & 0.80 \\
\hline
\end{tabular}

for self-regulation occurred, $F(2,117)=5.81, p<.01, \eta^{2}=.09$. No main effects could be found for instructional support for data interpretation, $F(2,117)=1.89, n s, \eta^{2}=.03$, and instructional support for self-regulation, $F(1,117)=.23, n s, \eta^{2}=.00$.

Perceived cognitive load

An analysis of variance for the first session with perceived cognitive load as the dependent variable and the instructional interventions as independent variables revealed significant main effects for instructional support for data interpretation, $F(2,118)=4.85, p<.01$, $\eta^{2}=.08$, and for instructional support for self-regulation, $F(1,118)=18.39, p<.001$, $\eta^{2}=.14$, as well as a significant interaction effect, $F(2,118)=10.57, p<.001, \eta^{2}=.15$. Furthermore, no significant main effect for instructional support for data interpretation, $F(2$, $112)=0.56, n s, \eta^{2}=.01$, but a significant effect for instructional support for self-regulation, $F(1,112)=9.98, p<.01, \eta^{2}=.08$, as well as a significant interaction effect, $F(2$, $112)=11.49, p<.001, \eta^{2}=.17$, could be found for the second posttest. The lowest scores of perceived cognitive load belonged to the learners of the conditions NS/NR, NS/R, and GeS/NR (see Table 4). For participants in the GeS/NR condition, a slight decrease in perceived cognitive load appeared from the first to the second session. Learners in the GiS/NR condition reported less cognitive load after the second session than after the first session with the computer program. After both sessions, learners in the NS/NR and NS/R conditions showed similar cognitive load scores. Learners in the GeS/R condition perceived the highest amount of cognitive load. In this condition, the learning gains were at the lowest level.

\section{Discussion}

Scientific discovery learning with computer simulations offers learners the opportunity to explore causal interrelations in dynamic systems in an active and self-regulated way. However, instructional support for learning with computer simulations is said to be useful for optimizing learners' interactions with the computer program and for enhancing knowledge acquisition. In this study, the focus was on the use of instructional interventions for data interpretation and self-regulation and their impact on learning outcomes. Apart from the control condition in which learners received no instructional support for data interpretation or for self-regulation, a significant domain-specific knowledge increase was observed after two learning sessions. More detailed analyses revealed differential effects of the instructional interventions for data interpretation and for self-regulation on knowledge acquisition. 
The best learning outcomes were found for learners who received either only instructional support for data interpretation or only instructional support for self-regulation. The learners' descriptions and interpretations of their own simulation outcome or the reflection of their own learning process turned out to be most effective. Getting a description and interpretation of the simulation outcome from the computer program and additionally reflecting on one's inquiry appeared effective as well. However, learners who were requested to describe, to interpret, and additionally to reflect on their own simulation outcomes had the smallest knowledge gains. It appears that a certain amount of instructional support can help learners to improve their performance in a multimedia learning environment. Beyond this point, the well-meant instructional interventions seem to have counter effects.

The hypothesis of a positive influence of instructional support for data interpretation on knowledge acquisition was partially supported. Describing and scientifically interpreting their own simulation outcome turned out to be the most effective instructional intervention for learners. It was more successful than receiving a justification for the simulation outcome or no further request to deal with the simulation results. Similar findings were obtained by Moreno and Mayer (2005), who showed the effectiveness of justifying the simulation outcome. Self-explanations can be induced by describing and interpreting one's own simulation outcome biologically. Chi and Bassok (1989) and Chi et al. (1994) have called this phenomenon the self-explanation effect. Self-explanation of new learning contents leads to better learning outcomes. In accordance, in a meta-analysis, Webb (1989) showed that when the learner was asked to provide elaborate explanations, positive effects on learning outcomes occurred, as opposed to when the learner received elaborative explanations. In addition, Wong et al. (2002) found positive effects for acquiring conceptual knowledge about a geometric theorem by eliciting self-explanations. The self-explanation effect is considered to be an active knowledge constructing process (Chi et al. 1994; Tajika et al. 2007; Wong et al. 2002). Generating explanations stimulates a deeper understanding and leads to higher learning outcomes because new information is suitably embedded into pre-existing knowledge structures. The self-explanation effect could be a reason for why describing and interpreting one's own simulation outcome led to higher knowledge gains than receiving the simulation result from the computer program or getting no support for data interpretation.

The hypothesis of a positive influence of instructional support for self-regulation could also be partially supported. The request to reflect on one's own inquiry as well as the simulation outcomes after conducting computer-simulated experiments had positive effects on students' domain-specific knowledge acquisition. Through reflection, learners were becoming aware of their own learning processes (van den Boom et al. 2004) and this might have contributed to more effective knowledge acquisition.

No cumulative effects concerning data interpretation and self-regulation could be found. A combination of instructional support for data interpretation and self-regulation did not lead to higher knowledge gains than supporting the learners with only one of these interventions. The research results show that a combination of instructional support for data interpretation and self-regulation can even have a negative impact on acquiring domain-specific knowledge. Learners who described, interpreted, and reflected on their own simulation outcome showed the lowest knowledge gains on the posttests.

The view on learners' perceived cognitive load offers an explanation for the reduced effectiveness of this combination (Sweller et al. 1998). By providing instructional support for learning with computer simulations, cognitive load is usually reduced (Leutner 1993). However, learners who described, interpreted, and reflected on their own simulation outcome assessed their perceived cognitive load much higher than learners in the other conditions. When the cognitive load is so high, less learning can be expected. The increased 
cognitive load could be a reason for why this specific combination of instructional interventions for data interpretation and self-regulation led to lower knowledge gains.

Learners in all six conditions were requested to work on concrete and well-structured assignments according to the inquiry cycle. By working through the assignments, learners focused on acquiring relevant fundamentals (Vreman-de Olde and de Jong 2006) on the topic of the water ecosystem. These fundamentals, to be discovered by means of the assignments and the computer simulation, were later tested by the knowledge posttest. It can be assumed that working on the assignments had a positive impact on students' knowledge acquisition (de Jong et al. 1994). Furthermore, it can be expected that offering learners permanent access to domain-specific information during the learning phases may have had positive effects on learners' knowledge acquisition (Leutner 1993). Additionally, the worked-out example integrated into the computer program may also have influenced the knowledge acquisition of learners as learning from worked-out examples is supposed to be effective for learning outcomes (Schworm and Renkl 2006). Therefore, the experimental conditions tested whether they performed better than the control condition with only basic support. It turned out that three of the five experimental conditions performed better than the control condition in which learners received no support for data interpretation or for self-regulation. The results demonstrate that instructional support is useful in different phases of the learning process and that an optimal result can be achieved only by the right amount and proper orchestration of the support processes. The question that needs to be answered by further research is how much instructional support for data interpretation and for self-regulation is required to adequately foster learners on the one hand and to avoid simultaneously overloading them on the other hand.

The present study involved secondary school students possessing a small amount of prior knowledge about ecology and learning with scientific discovery simulations. It is possible that several of these learners could have been overstrained by learning about the complex concept of the relationship between two species by conducting experiments via a computer simulation and additionally accomplishing the particular instructional interventions for data interpretation and for self-regulation. It can be assumed that prior knowledge may have an influence on participants' abilities to work on the instructional interventions as well. Concerning this matter, particular instructional support for data interpretation and for self-regulation can cause a reversal effect on knowledge acquisition, especially for learners with a large amount of prior knowledge (cf. Kalyuga 2007). To draw a conclusion about this phenomenon, further investigations with undergraduate students may provide meaningful results.

In conclusion, we were able to show that particular instructional interventions for data interpretation and self-regulation can effectively support learning with scientific computer simulations. Supporting learning with computer simulations with only one instructional intervention - either for data interpretation or for self-regulation-proved to be especially effective. In this regard, having learners describe and biologically interpret their own simulation outcome seems to be the most effective instructional intervention concerning domain-specific knowledge acquisition. The learners' opportunity to assess their own inquiry and additionally to reflect about their own simulation outcomes showed positive learning effects as well. However, the results indicate that "too much" instructional support can even constrain knowledge acquisition when learning with computer simulations. Consequently, an appropriate instructional design should be chosen to avoid cognitively overloading learners and to support effective knowledge acquisition.

Acknowledgment This research project was funded by the German Research Foundation (DFG), Germany. 
Open Access This article is distributed under the terms of the Creative Commons Attribution License which permits any use, distribution, and reproduction in any medium, provided the original author(s) and the source are credited.

\section{Appendix}

Example of a Concrete Assignment to Stimulate the Generation of a Solution

The baron brings a special concentrated feed to the lake, which promotes the increase of the rudds. The increase of the rudds rises by a value of " 10 " per month. After 20 months, the baron checks the stocks of fishes. What will have happened to the number of rudds and pikes?

a) Make a prediction.

\begin{tabular}{|l|l|}
\hline The number of rudds... & The number of pikes... \\
\hline$\square \ldots$...decreases. & $\square$...decreases. \\
\hline$\square \ldots$...stays the same. & $\square$...stays the same. \\
\hline$\square \ldots$...increases. & $\square$...increases. \\
\hline
\end{tabular}

b) Run the simulation in the provided task above and compare with the control graph.

\begin{tabular}{|l|l|}
\hline $\begin{array}{l}\text { After } \mathbf{2 0} \text { months, the number of } \\
\text { rudds... }\end{array}$ & $\begin{array}{l}\text { After } \mathbf{2 0} \text { months, the number of } \\
\text { pikes... }\end{array}$ \\
\hline$\square$...decreased. & $\square$...decreased. \\
\hline$\square$...stayed the same. & $\square$...stayed the same. \\
\hline$\square \ldots$...increased. & $\square$...increased. \\
\hline
\end{tabular}

c) Examine whether your prediction in (a) matches the result of the simulation in (b).
$\square$ Yes
$\square$ No

d) Describe your simulation outcome:

Interpret your simulation outcome biologically: 


\section{References}

Anderson, L. W., \& Krathwohl, D. R. (Eds.). (2001). A taxonomy for learning, teaching, and assessing: A revision of Bloom's taxonomy of educational objectives. New York: Longman.

Atkinson, R. K., Derry, S. J., Renkl, A., \& Wortham, D. (2000). Learning from examples: Instructional principles from the worked examples research. Review of Educational Research, 70, 181-214.

Biesinger, K., \& Crippen, K. (2010). The effects of feedback protocol on self-regulated learning in a webbased worked example learning environment. Computers \& Education, 55, 1470-1482.

Blake, C., \& Scanlon, E. (2007). Reconsidering simulations in science education at a distance: Features of effective use. Journal of Computer Assisted Learning, 23, 491-502.

Bruner, J. S. (1961). The act of discovery. Harvard Educational Review, 31, 21-32.

Byrnes, J. P., \& Wasik, B. A. (1991). Role of conceptual knowledge in mathematical procedural learning. Developmental Psychology, 27, 777-786.

Chi, M. T. H., \& Bassok, M. (Eds.). (1989). Learning from examples via self-explanations. Hillsdale, NJ: Erlbaum.

Chi, M. T. H., Bassok, M., Lewis, M. W., Reimann, P., \& Glaser, R. (1989). Self-explanations: How students study and use examples in learning to solve problems. Cognitive Science, 13, 145-183.

Chi, M. T. H., de Leeuw, N., Chiu, M. H., \& La Vancher, C. (1994). Eliciting self-explanations improves understanding. Cognitive Science, 18, 439-477.

Cook, L. M. (1993). Hunt: A simulation of predator searching behavior. Journal of Biological Education, 27, 287-290.

de Jong, T. (2006). Computer simulations: Technological advances in inquiry learning. Science, 312, $532-533$.

de Jong, T. (2010). Cognitive load theory, educational research, and instructional design: Some food for thought. Instructional Science, 38, 105-134.

de Jong, T., \& Njoo, M. (1992). Learning and instruction with computer simulations: Learning processes involved. In E. de Corte, M. Linn, H. Mandl, \& L. Verschaffel (Eds.), Computer-based learning environments and problem solving (pp. 411-429). Berlin: Springer.

de Jong, T., \& van Joolingen, W. R. (1998). Scientific discovery learning with computer simulations of conceptual domains. Review of Educational Research, 68, 179-202.

de Jong, T., van Joolingen, W., Scott, D., de Hoog, R., Lapied, L., \& Valent, R. (1994). SMISLE: System for multimedia integrated simulation learning environments. In T. de Jong \& L. Sarti (Eds.), Design and production of multimedia and simulation-based learning material (pp. 133-165). Dordrecht: Kluwer Academic Publishers.

de Jong, T., van Joolingen, W. R., Swaak, J., Veermans, K., Limbach, R., King, S., et al. (1998). Selfdirected learning in simulation-based discovery environments. Journal of Computer Assisted Learning, $14,235-246$.

Elshout, J. J., \& Veenman, M. V. J. (1992). Relation between intellectual ability and working method as predictors of learning. Journal of Educational Research, 85, 134-143.

Finley, F. N., Steward, J., \& Yarroch, N. L. (1982). Teachers' perceptions of important difficult science content. Science Education, 66, 531-538.

Gallegos, L., Jerezano, M. E., \& Flores, F. (1994). Preconceptions and relations used by children in the construction of food chains. Journal of Research in Science Teaching, 31, 259-272.

Griffiths, A. K., \& Grant, B. A. C. (1985). High school students' understanding of food webs: Identification of a learning hierarchy and related misconceptions. Journal of Research in Science Teaching, 22, 421-436.

Kalyuga, S. (2007). Expertise reversal effect and its implications for learner-tailored instruction. Educational Psychology Review, 19, 509-539.

Kalyuga, S., Chandler, P., Tuovinen, J., \& Sweller, J. (2001). When problem solving is superior to studying worked examples. Journal of Educational Psychology, 93, 579-588.

Kirschner, P. A., Sweller, J., \& Clark, R. E. (2006). Why minimal guidance during instruction does not work: An analysis of the failure of constructivist, discovery, problem-based, experiential, and inquirybased teaching. Educational Psychologist, 41, 75-86.

Klahr, D., \& Dunbar, K. (1988). Dual space search during scientific reasoning. Cognitive Science, 12, 1-48.

Klahr, D., Fay, A. L., \& Dunbar, K. (1993). Heuristics for scientific experimentation: A developmental study. Cognitive Psychology, 25, 111-146.

Leutner, D. (1993). Guided discovery learning with computer-based simulation games: Effects of adaptive and non-adaptive instructional support. Learning and Instruction, 3, 113-132. 
Lewis, E. L., Stern, J. L., \& Linn, M. C. (1993). The effect of computer simulations on introductory thermodynamics understanding. Educational Technology, 33, 45-58.

Lin, X., \& Lehmann, J. D. (1999). Supporting learning of variable control in a computer-based biology environment: Effects of prompting college students to reflect on their thinking. Journal of Research in Science Teaching, 36, 837-858.

Lutterschmidt, W. I., \& Schaefer, J. F. (1997). A computer simulation for demonstrating and modelling predator-prey oscillations. Journal of Biological Education, 31, 221-227.

Manlove, S., Lazonder, A. W., \& de Jong, T. (2006). Regulative support for collaborative scientific inquiry learning. Journal of Computer Assisted Learning, 22, 87-98.

Mayer, R. E. (2004). Should there be a three-strikes rule against pure discovery learning? The case for guided methods of instruction. American Psychologist, 59, 14-19.

Miller, G. A. (1956). The magical number seven, plus or minus two: Some limits on our capacity for processing information. Psychological Review, 63, 81-97.

Moreno, R. (2004). Decreasing cognitive load for novice students: Effects of explanatory versus corrective feedback in discovery-based multimedia. Instructional Science, 32, 99-113.

Moreno, R., \& Mayer, R. E. (2005). Role of guidance, reflection and interactivity in an agent-based multimedia game. Journal of Educational Psychology, 97, 117-128.

National Research Council. (1996). National science education standards. Washington, DC: National Academy Press.

Nerdel, C., \& Prechtl, H. (2004). Learning complex systems with simulations in science education. In P. Gerjets, P. A. Kirschner, J. Elen, \& R. Joiner (Eds.), Instructional design for effective and enjoyable computer-supported learning: Proceedings of the first joint meeting of the EARLI SIGs "Instructional Design" and "Learning and Instruction with Computers" (pp. 160-177) [CD-ROM]. Tuebingen: Knowledge Media Research Center.

Paas, F. G. W. C. (1992). Training strategies for attaining transfer of problem-solving skill in statistics: A cognitive-load approach. Journal of Educational Psychology, 84, 429-434.

Reid, D. J., Zhang, J., \& Chen, Q. (2003). Supporting scientific discovery learning in a simulation environment. Journal of Computer Assisted Learning, 19, 9-20.

Renkl, A. (2005). The worked-out example principle in multimedia learning. In R. Mayer (Ed.), Cambridge handbook of multimedia learning (pp. 229-246). Cambridge: Cambridge University Press.

Renkl, A., \& Atkinson, R. K. (2002). Learning from examples: Fostering self-explanations in computerbased learning environments. Interactive Learning Environments, 10, 105-119.

Rey, G. D. (2010). Instructional advice, time advice and learning questions in computer simulations. Australasian Journal of Educational Technology, 26(5), 675-689.

Rieber, L. P., \& Parmley, M. W. (1995). To teach or not to teach? Comparing the use of computer-based simulations in deductive versus inductive approaches to learning with adults in science. Journal of Computing Research, 13, 359-374.

Schworm, S., \& Renkl, A. (2006). Computer-supported example-based learning: When instructional explanations reduce self-explanations. Computers \& Education, 46, 426-445.

Sweller, J. (2005). Implications of cognitive load theory for multimedia learning. In R. E. Mayer (Ed.), The Cambridge handbook of multimedia learning (pp. 19-30). Cambridge: Cambridge University Press.

Sweller, J., van Merriënboer, J. J. G., \& Paas, F. G. W. C. (1998). Cognitive architecture and instructional design. Educational Psychology Review, 10, 251-296.

Tajika, H., Nakatsu, N., Nozaki, H., Ewald, N., \& Shunichi, M. (2007). Effects of self-explanation as a metacognitive strategy for solving mathematical word problems. Japanese Psychological Research, 49, 222-233.

Urhahne, D. (2002). Motivation und Verstehen [Motivation and understanding]. Münster: Waxmann.

Urhahne, D., \& Harms, U. (2006). Instruktionale Unterstützung beim Lernen mit Computersimulationen [Instructional support for learning with computer simulations]. Unterrichtswissenschaft, 34, 358-377.

Urhahne, D., Prenzel, M., von Davier, M., Senkbeil, M., \& Bleschke, M. (2000). Computereinsatz im naturwissenschaftlichen Unterricht - Ein Überblick über die pädagogisch-psychologischen Grundlagen und ihre Anwendung [Computer use in science education-An overview of the psychological and educational foundations and its applications]. Zeitschrift für Didaktik der Naturwissenschaften, 6, $157-186$.

van den Boom, G., Paas, F., van Merriënboer, J., \& van Gog, Y. (2004). Reflection prompts and tutor feedback in a web-based learning environment: Effects on students' self-regulated learning competence. Computers in Human Behavior, 20, 551-567.

van Joolingen, W. R., \& de Jong, T. (1997). An extended dual search space model of scientific discovery learning. Instructional Science, 25, 307-346. 
van Joolingen, W. R., de Jong, T., \& Dimitrakopoulou, A. (2007). Issues in computer supported inquiry learning in science. Journal of Computer Assisted Learning, 23, 111-119.

van Joolingen, W. R., de Jong, T., Lazonder, A. W., Savelsbergh, E. R., \& Manlove, S. (2005). Co-Lab: Research and development of an online learning environment for collaborative scientific discovery learning. Computers in Human Behavior, 21, 671-688.

van Joolingen, W. R., King, S., \& de Jong, T. (1997). The SimQuest authoring system for simulation-based discovery learning. In B. du Boulay, \& R. Mizoguchi (Eds.), Artificial intelligence in education (pp. 79-86). IOS Press.

Vreman-de Olde, C., \& de Jong, T. (2006). Scaffolding learners in designing investigation assignments for a computer simulation. Journal of Computer Assisted Learning, 22, 63-73.

Webb, N. M. (1989). Peer interaction and learning in small groups. International Journal of Education Research, 13, 21-39.

White, B. (1998). Computer microworlds and scientific inquiry: An alternative approach to science education. In B. Fraser \& K. Tobin (Eds.), International handbook of science education (pp. 295-315). Dordrecht: Kluwer.

White, B., \& Frederiksen, J. R. (1998). Inquiry, modeling, and metacognition: Making science accessible to all students. Cognition and Instruction, 16, 3-118.

White, R. T., \& Gunstone, R. F. (1992). Probing understanding. Great Britain: Falmer Press.

White, B., Shimoda, T. A., \& Frederiksen, J. R. (1999). Enabling students to construct theories of collaborative inquiry and reflective learning: Computer support for metacognitive development. International Journal of Artificial Intelligence in Education, 10, 151-182.

Wong, R. M. F., Lawson, M. J., \& Keeves, J. (2002). The effects of self-explanation training on students' problem solving in high-school mathematics. Learning and Instruction, 12, 233-262.

Yaman, M., Nerdel, C., \& Bayrhuber, H. (2008). The effects of instructional support and learner interests when learning using computer simulations. Computers \& Education, 51, 1784-1794.

Zhang, J., Chen, Q., Sun, Y., \& Reid, D. J. (2004). Triple scheme of learning support design for scientific discovery learning based on computer simulation: Experimental research. Journal of Computer Assisted Learning, 20, 269-282.

Zimmermann, B. J., Bonner, S., \& Kovach, R. (1996). Developing self-regulated learners: Beyond achievement to self-efficacy. Washington: APA.

Zimmermann, B. J., \& Tsikalas, K. E. (2005). Can computer-based learning environments (CBLEs) be used as self-regulatory tools to enhance learning? Educational Psychologist, 40, 267-271. 